\title{
ARTIGO
}

\section{A REDE SOCIAL COMO ESPAÇO PARA A DISCUSSÃO E APRENDIZAGEM DE CONCEITOS BÁSICOS DA MATEMÁTICA ${ }^{1}$}

\author{
Márcio Antônio Souza Paim² \\ Midiele Dantas Gomes \\ André Ricardo Magalhães
}

\begin{abstract}
RESUMO
Este trabalho tem como objetivo analisar o processo de aprendizagem de um grupo de alunos da Educação de Jovens e Adultos do curso técnico em Segurança do Trabalho do Instituto Federal da Bahia, campus Santo Amaro, quando discutem conceitos básicos de matemática numa mídia social representada pelo aplicativo WhatsApp. Buscando identificar os tipos de dúvidas geradas pelos alunos no estudo da matemática básica, foram listados os registros dos estudantes que mais contribuíram com as discussões no grupo. Se apropriando dos conceitos teóricos da Cibercultura, Ideografia Dinâmica, Linked e da Análise de rede para mídia social, foi construída uma rede apresentando seus nós e a relação quantitativa entre os mesmos. A pesquisa tem caráter qualiquantitativo quando discute a participação individual de cada aluno no ambiente tecnológico e o seu questionamento em relação aos conceitos matemáticos propostos pelo professor. Os resultados desse trabalho indicam que a mídia social pode funcionar como um importante ambiente de discussão e aprendizagem da matemática.
\end{abstract}

Palavras-chave: Matemática básica. Mídia social. Análise de rede.

\section{INTRODUÇÃO}

As redes sociais têm se revelado, nos últimos anos, uma complexa cadeia de fenômenos comunicativos que se correlacionam através do grande acesso à internet. Considerando que o surgimento ou análise das redes sociais seja algo totalmente novo, o seu reengajamento no espaço das comunicações virtuais evidencia novos elementos e dinâmicas para seu estudo (RECUERO, 2009; BENEVENUTO, 2010; MALINI; ANTOUN, 2013).

As interações na internet permitem que esses processos dinâmicos funcionem de acordo com o surgimento dos sites e aplicativos de rede social, organizando e transformando o cenário das redes com registros de dinâmicas sociais. Esses registros possibilitam que relações e diálogos possam ser mapeados e analisados em grande escala, como por exemplo, o estudo de conceitos básicos da matemática.

Neste trabalho, pretendemos analisar a aprendizagem de um grupo de estudantes da EJA, no curso em Segurança do Trabalho do Instituto Federal da Bahia (IFBA), campus de Santo Amaro, quando discutem conceitos de matemática básica numa mídia social. Tal interação ocorreu no ano de 2016, durante a primeira disciplina de matemática do curso (Matemática para a

\footnotetext{
${ }^{1}$ Como citar este artigo: PAIM, Márcio Antônio Souza; GOMES, Midiele Dantas; MAGALHÃES, André Ricardo. A rede social como espaço para a discussão e aprendizagem de conceitos básicos da matemática. ForScience: revista científica do IFMG, Formiga, v. 6, n. 1, e00339, jan./jun. 2018.

${ }^{2}$ Autor para correspondência: Márcio Antônio Souza Paim, IFBA - Campus Santo Amaro, e-mail: maspaim@hotmail.com.
} 
Segurança do Trabalho) a partir das dúvidas de 14 estudantes às sugestões de atividades propostas pelo professor da disciplina, utilizamo-nos do estudo da

Análise de Redes Sociais (ARS), mais especificamente, da rede social na Internet para listar o registro dos diálogos dos estudantes que participaram da dinâmica no ambiente do aplicativo WhatsApp.

Optamos pela ferramenta tecnológica WhatsApp para possibilitar a todos os alunos uma educação à distância, que pudesse esclarecer os seus questionamentos fora da sala de aula e por ser um aplicativo de uso livre a todo público com acesso à internet, permitindo que o usuário o utilize de qualquer lugar, em qualquer hora e em locais distantes da escola, como nas residências dos estudantes.

Essa tecnologia é gratuita e bem conhecida entre os alunos. Ao saber que já a utilizavam para a troca de informações sem fins educacionais, como a criação de grupos de amizade e afinidades em comum, o professor de matemática da turma resolveu aproveitar esse espaço a distância para realização de atividades de matemática com seus alunos.

Assim, para delineamento do nosso estudo, explicaremos a seguir o significado de conceitos como "Cibercultura" e o "Ciberespaço" de onde emergiram as redes, para depois discutirmos sobre a sua constituição e composição.

\section{CONCEITOS TEÓRICOS DE SUSTENTAÇÃO DO TRABALHO:}

\subsection{Cibercultura}

Conceituaremos esse termo segundo o filósofo francês Pierry Lévy (1999), que trata a internet como um fenômeno cultural. Além disso, o autor também apresenta o conceito de "Ciberespaço" que ele aborda como sendo a infraestrutura material da comunicação digital e tudo que abrange esse mundo de informações como, por exemplo, os indivíduos que o alimentam. Cibercultura é "o conjunto de técnicas (materiais e intelectuais), de práticas, de atitudes, de modos de pensamento e de valores que se desenvolvem juntamente com o crescimento do ciberespaço" (LÉVY, 1999, p. 17). Atuando assim, como um grande fluxo causado pelas evoluções tecnológicas das telecomunicações, especificamente, com o surgimento da internet.

A infraestrutura técnica do que vem a ser virtual perpassa por alguns processos que Lévy (1999) denomina como: tratamento, memória, transmissão, interfaces, programação e programas. O tratamento das informações que hoje encontramos através de chips, é responsável por efetuar cálculos aritméticos e lógicos; a memória é o suporte de gravação e leitura automáticas de informações.

A transmissão de informações digitais pode ser feita fisicamente através de dispositivos como discos, CDs, pen drives, como também por conexão direta em rede on-line. As interfaces, que são os aparatos materiais, permitem a interação entre o universo da informação digital e o mundo ordinário, a execução de tarefas por softwares e aplicativos de programas oferecem 
serviços específicos para os seus usuários. Além disso, a Cibercultura se apresenta como um movimento social. Baseado nisso:

A emergência do ciberespaço é um fruto de um verdadeiro movimento social, com seu grupo líder (a juventude metropolitana escolarizada), suas palavras de ordem (interconexão, criação de comunidades virtuais, inteligência coletiva) e suas aspirações. (LÉVY, 1999, p. 123)

Os princípios da interconexão, criação de comunidades virtuais e a inteligência coletiva orientam o crescimento inicial do ciberespaço. Para a Cibercultura a tendência da interconexão causa uma mudança física da comunicação, onde passa das noções de canal e rede para uma sensação de espaço envolvente, ou seja, este local tornou-se um canal de comunicação interativa; as comunidades virtuais surgem da interconexão, que é construída de acordo com afinidades de interesses, de conhecimentos em comum em um regime de cooperação mútua. Por fim, a inteligência coletiva é a última finalidade do Ciberespaço. Ela é constituída por uma inteligência compartilhada através da cooperação de diversos indivíduos em suas diversidades.

Portanto, esse trabalho apresenta exemplos dos conceitos apresentados por Lévy (1999), sendo composta de uma rede social de alunos que possuem os mesmos interesses de aprendizagem. Caso determinado assunto pareça mais complexo para o estudante, é possível que as dúvidas sejam por meio de um compartilhamento de informações e cooperação mútua entre os sujeitos desse ambiente tecnológico.

\subsection{Ideografia Dinâmica}

Lévy (1998) apresenta a noção da Ideografia Dinâmica (ID) e tem como base as interações entre a sociedade e os meios de comunicação em tecnologias de realidade virtual sugerindo a necessidade de uma sociedade informatizada, midiática e crítica e, além disso, imaginativa.

Ele apresenta a imagem como uma tecnologia intelectual, que seria o apoio de toda ideia inovadora da Ideografia Dinâmica, ou seja, aborda o aparecimento de uma nova escrita, e enfatiza essa teoria descrevendo que as tecnologias informáticas serão a base desse novo tipo de linguagem. $\mathrm{O}$ autor cita a linguagem cinematográfica como um espaço onde todos os elementos remetem a um significado, a televisão ou tela de cinema.

Porém, essas ferramentas ainda são limitadas e não permitem uma troca de informações consistentes com o espectador. Assim, Lévy (1998) afirma que o computador pode se apresentar como ideal para essa interação de imagem abstrata, deslocando assim, o receptor para uma realidade abstrata; a realidade virtual.

É importante lembrar que, com o surgimento dos livros, não se extinguiu a capacidade intelectual humana, assim como o computador não o fará, e ainda:

$\mathrm{Na}$ realidade virtual podemos criar o mundo e partilhá-lo com outras pessoas. Muito mais que descrever algo a um parceiro, podemos dar-lhe uma experiência sensorial. [...] $\mathrm{Na}$ realidade virtual, teremos ferramentas que nos permitirão transformar o mundo muito 
rapidamente segundo estilos de causalidade variados. Seremos capazes de improvisar a realidade. A composição do mundo tornar-se-á ato de comunicação por excelência, à medida que a realidade (virtual) seja transformada de maneira cooperativa (LÉVY, 1998, p. 29-30).

Da mesma forma que os computadores ditos tradicionais, os smartphones, que são hoje os minicomputadores portáveis, podem colaborar com essa nova linguagem interativa, exemplo de linguagem que trataremos no decorrer do trabalho.

Para Lévy (1998), só é possível que haja uma real comunicação quando os interlocutores são capazes de compreender e interpretar os enunciados que lhes são apresentados. Sendo assim, o autor apresenta a Ideografia Dinâmica, através da ferramenta computador, capaz de permitir uma linguagem ou escrita alfabética que represente uma situação da realidade. Da mesma maneira, a comunicação dos alunos através de um aplicativo digital, não é desvinculada das linguagens oral e escrita, elas se complementam.

\subsection{Linked}

Barabási (2009) afirma que somos uma sociedade em rede. O autor discorre sobre o conceito e as regras que compõe as redes e, de alguma maneira, nós seres humanos, estamos sempre conectados (linked) a algo. Nas relações interpessoais as pessoas deste planeta estão ligadas por interesses em comum, assim como existem conexões das mais diversas por meio de artigos científicos, ligações telefônicas e ocorrência de doenças de uma determinada população. A rede representa uma teia composta por "nós" (elementos) e "links" (conexões) entre esses nós. Para exemplificar, em uma rede social como o WhatsApp, as pessoas seriam os nós e as interações com as outras pessoas seriam os links. Tudo isso constitui uma rede que é frequentemente apontada como uma metáfora para o estudo dos sistemas complexos (BARABÁSI, 2009).

Na sociedade, a maior parte das redes é dinâmica e isso se dá porque seus elementos estão em constantes transformações, modificando-se a origem e a chegada dos mesmos, como também, a remodelagem das conexões entre os elementos interligados. A organização que se constitui em diversas redes faz com que elas venham a ser conceituadas como sistemas complexos. Da mesma maneira, diversos sistemas mais complexos podem ser analisados e investigados como redes.

Para Barabási (2009, p. 6-16), os elementos que fazem parte da rede se interligam como um "complexo quebra-cabeça", onde diversos mundos pequenos se encadeiam uns aos outros. $\mathrm{Na}$ sociedade, por exemplo, o autor notou que nós estamos inseridos em um vasto aglomerado de redes nas quais ninguém pode ser excluído. Portanto, a configuração de redes permite que seja possível desenhar mapas que se mostram como sistemas dinâmicos e complexos.

\subsection{Análise de Redes Sociais (ARS)}


A ARS é basicamente um mecanismo de análise de dados que evidencia especialmente a clareza dessas informações dentro do ponto de vista de sua estrutura, que é a rede. Segundo Recuero (2009), ela tem o propósito de investigar as conexões entre os dados que são coletados de grupos sociais, logo vem a denominação: "redes sociais". É um procedimento que tem como ponto central inicial a análise quantitativa, que procura colher propriedades dessas conexões e dos atores inseridos nesse sistema e, além disso, examinar essas propriedades gerais da rede. Desse modo, a análise se apresenta principalmente de forma numérica.

Assim, a ARS observa as informações de um dado grupo como nós e conexões e apresenta formas de interpretação desses elementos com relação à rede, funcionando para grupos de dados onde interessam as relações entre os objetos e não estes em si. Ela pode oferecer pequenos dados para analisar perfis de uma determinada rede social como a desenvolvida pelo software WhatsApp, mas é relevante para compreender como esses perfis se conectam e se relacionam.

\section{PROPOSTA METODOLÓGICA}

Para analisar as interações entre os estudantes e o professor dentro do ambiente tecnológico, buscamos utilizar a análise de redes sociais para dar subsídio ao nosso trabalho. Nessa proposta, adotamos o grupo social, representado pelo professor de matemática e os 14 alunos da turma 1, definidos simbolicamente por A1 até A14, do primeiro semestre do curso técnico em Segurança do Trabalho do IFBA, campus de Santo Amaro, como os atores que trocam as informações no grupo. Segundo Goulart (2014), a importância da análise de redes sociais se insere nas relações entre os atores que interagem entre si.

Os atores que utilizam o Ciberespaço, representado aqui pelo WhatsApp, podem compartilhar informações, ideias e atividades de matemática. Logo, o foco principal desse trabalho está em verificar a aprendizagem de conceitos básicos de matemática pelos alunos da EJA, enquanto atores em uma rede de informações através da internet. Para Goulart (2014, apud HANNEMAN; RIDDLE, 2005), os atores podem ser pessoas ou empresas que estão relacionadas por alguma atividade, além de grupos, localidades, cidades, regiões, entre outros.

Sabemos que numa rede de pesca existem malhas nas quais os seus laços são unidos por nós. Assim como há vários nós nesse tipo de rede, os links numa mídia social conectam os alunos e os conceitos matemáticos entre si por meio de informações que, nesse caso, são as respostas dadas ou dúvidas geradas pelos próprios alunos. As atividades propostas no ambiente tecnológico ocorreram fora do ambiente da sala de aula. Nesse caso, já em suas casas, distantes da escola, todos os estudantes estavam com seus dispositivos móveis (smartphones) com acesso a internet.

Diante disso, iniciamos a atividade onde os alunos da turma foram dispostos no ambiente como pontos de uma teia que os conecta. As discussões sobre conceitos de matemática básica, como os números racionais e as expressões numéricas, caracterizam-se como uma rede de informações. Essa troca ocorreu através de perguntas feitas pelo professor e as respostas dadas 
pelos alunos. O auxílio às dúvidas destes foi proporcional à sua participação na mídia social. Sendo assim, é razoável supor que, quanto maior sua interação e procura em responder as perguntas, maior a possibilidade de compreensão do conteúdo.

A partir daí, surgem relações que fazem parte de um conjunto inicial de três categorias de análise: $1^{\text {a }}$ ) o conteúdo matemático estudado (sugestão de atividades propostas pelo professor sobre os números racionais e as expressões numéricas com números racionais, ...); $2^{\mathrm{a}}$ ) os atores da relação (o professor de matemática e os 14 alunos da turma 1); $3^{\mathrm{a}}$ ) as respostas dos alunos (respostas às atividades sugeridas pelo professor ou dúvidas e questionamentos quanto aos conteúdos estudados; operações e propriedades do números racionais, as frações decimais e a composição das expressões numéricas com números naturais).

Para ilustrar, esboçamos a seguir as classificações por meio de um esquema que relaciona a sugestão de atividades e respostas, respectivamente, registradas pelo professor e pelos alunos dentro do ambiente tecnológico:

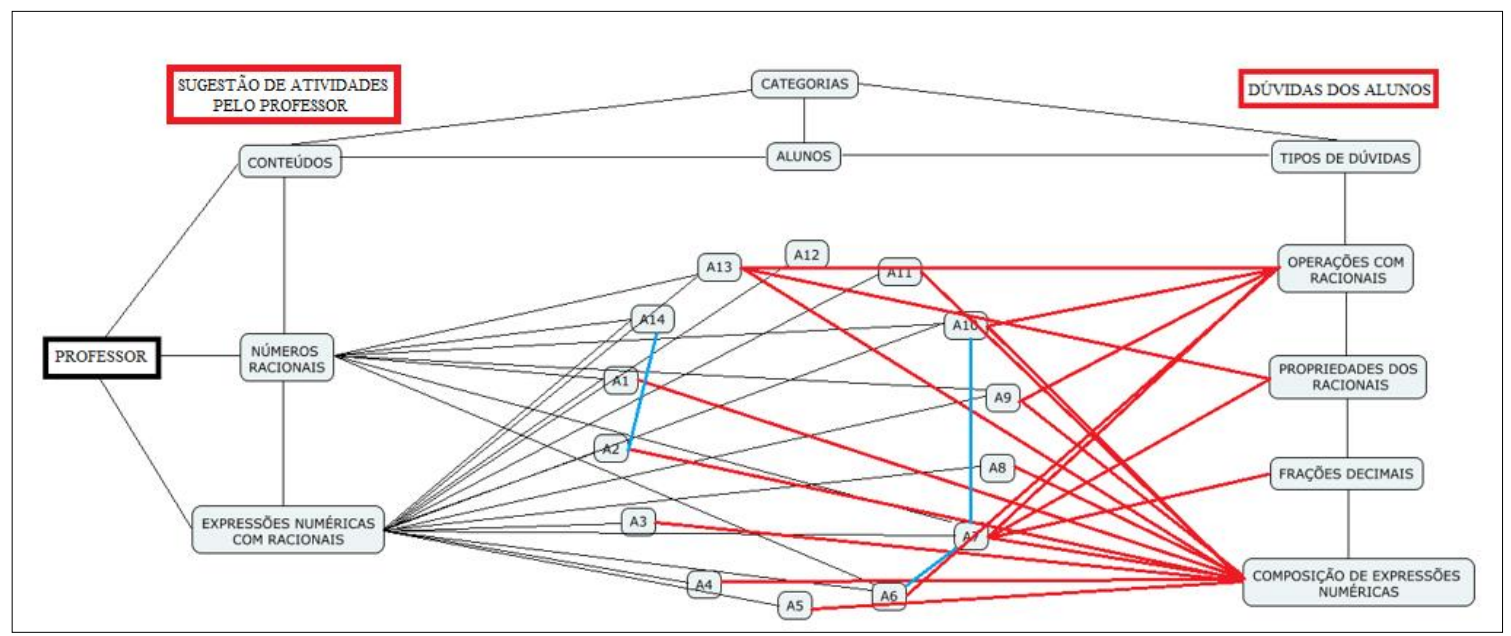

Figura 1 - Esboço da relação entre os atores da rede Fonte: Elaborado pelos autores.

As flechas com as linhas de cor cinza indicam o envio de perguntas sobre números racionais e expressões numéricas feitas pelo professor aos alunos. Cada aluno recebeu flechas de pelo menos um desses conteúdos e como geralmente o conteúdo dos racionais precede o das expressões numéricas, uma vez que a expressão numérica é constituída de números racionais, as primeiras perguntas feitas foram sobre os números racionais.

As flechas com as linhas na cor azul refletem as interações diretas ou indiretas entre os alunos. Nesse caso, registramos de modo mais significativo, as interações entre A2 e A14, e entre A6, A7 e A10, pois a maioria estava mais ocupada em responder às perguntas elaboradas pelo professor.

As flechas avermelhadas representam quatro tipos de respostas dadas ou dúvidas geradas. A maioria dos alunos conseguiu responder questões sobre a composição de expressões numéricas. Estas são questões relativas à construção de uma expressão numérica a partir da contagem de objetos encontrados no cotidiano, como no exemplo abaixo: 


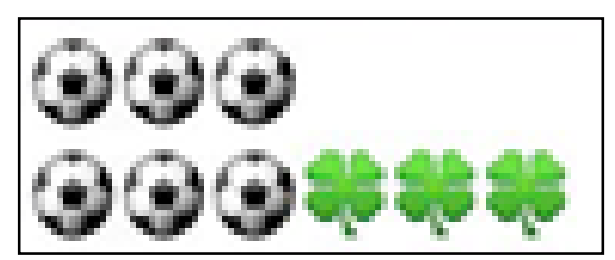

Figura 2 - Exemplo de duas coleções de objetos Fonte: Elaborado pelos autores.

Espera-se que o aluno perceba que ele pode construir uma simples expressão numérica contando os elementos destes dois conjuntos (o conjunto de 6 bolas e de 3 trevos). Dessa forma, ao contar ao todo os 9 elementos do conjunto, ele poderá escrever uma expressão reunindo os dois grupos de elementos parciais: $(2 \times 3)$ bolas $+\left(\begin{array}{l}1 \times 3\end{array}\right)$ trevos, resultando na expressão numérica: $2 \times 3+1 \times 3$. Mais adiante, um outro exemplo dessa questão pode ser visto nos quadros de diálogo do professor e dos alunos "printados" da área de trabalho do Whatsapp.

A partir dos exemplos de expressões numéricas construídas pelo professor de matemática da turma 1, formadas por outros objetos ou símbolos disponíveis no ambiente do aplicativo, os estudantes também construíram expressões numéricas similares. Logo, acreditamos que essa dinâmica pôde auxiliar os alunos no entendimento do significado de uma expressão numérica.

Inicialmente, as principais dúvidas e questionamentos dos alunos estavam nas propriedades e operações dos números racionais, como por exemplo, ao dividir a fração $\frac{1}{2}$ por $\frac{5}{7}$.

A seguir, foram selecionadas algumas das conversas sobre os números racionais e as expressões numéricas ocorridas no ambiente tecnológico da rede social. As falas dos alunos se encontram nos retângulos brancos e a do professor nos retângulos esverdeados:

\begin{tabular}{|c|c|}
\hline \multirow{2}{*}{\multicolumn{2}{|c|}{$\begin{array}{l}\text { A7 } \\
\text { Boa tarde!!! Alguem m tira uma }\end{array}$}} \\
\hline & \\
\hline dúvida? & $15: 57$ \\
\hline \multicolumn{2}{|c|}{$\begin{array}{l}\text { Quando na operação tem pra } \\
\text { dividir, sempre inverte o segundo }\end{array}$} \\
\hline numero eh? & $15: 57$ \\
\hline \multicolumn{2}{|c|}{ Pelo oq vi aqui eh na que inverte. } \\
\hline Dps de faz isso ai. & $15: 57$ \\
\hline \multicolumn{2}{|c|}{$\begin{array}{l}\text { Mas nao sei se pode inverter o } \\
\text { primeiro numero. }\end{array}$} \\
\hline & \\
\hline Na divisão & \\
\hline
\end{tabular}

Figura 3 - Dúvida da aluna A7 com resposta do professor Fonte: Elaborado pelos autores.

A dúvida gerada, mostrada pelo diálogo direto de A7 com o professor, vem acompanhada da resposta reforçada por A6. Isso justifica a flecha azul entre elas mostrada na Figura 1: 


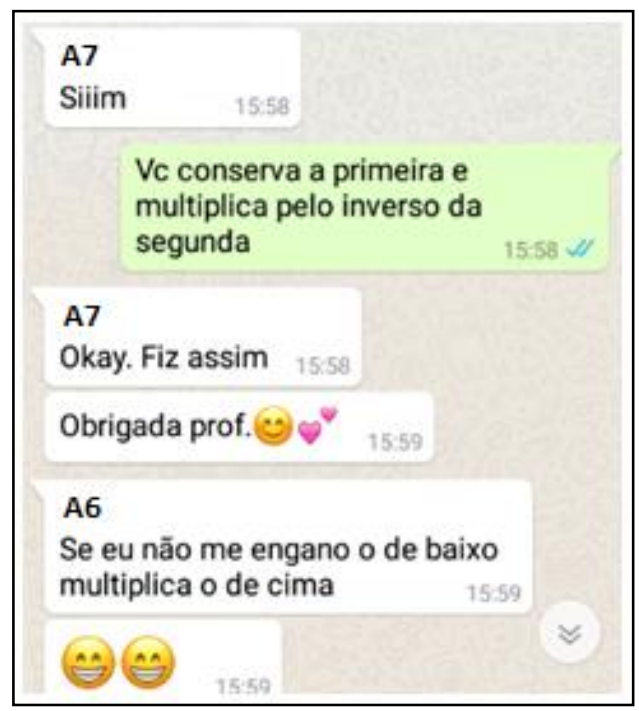

Figura 4 - Resposta do professor a A7 com participação de A6 Fonte: Elaborado pelos autores.

A dúvida de A7 parece ser sanada depois que o professor sugere sobre a operacionalização das frações:

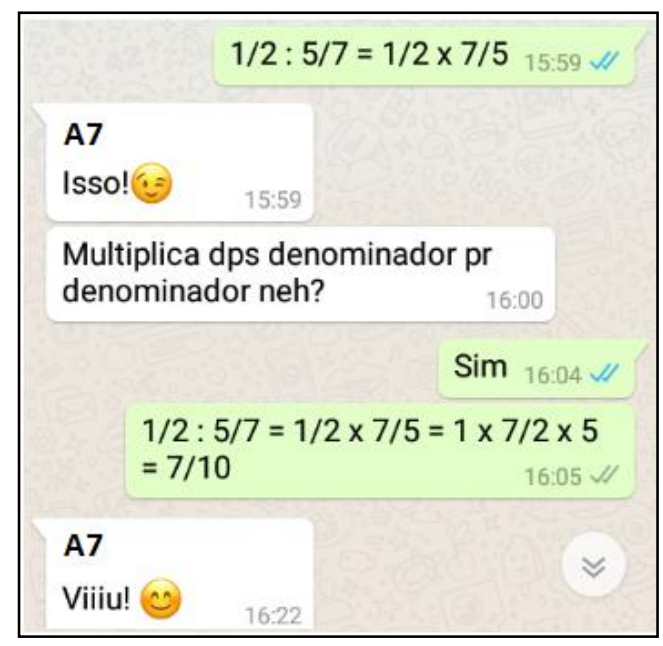

Figura 5 - Dúvida sanada pelo professor a A7 Fonte: Elaborado pelos autores.

De uma maneira geral, os números racionais são todos aqueles escritos na forma $\frac{a}{b}$, sendo $a$ e $b$ números inteiros, com $b \neq 0$. Os obstáculos à aprendizagem surgem quando os estudantes se deparam com as frações decimais, aquelas em que o denominador da fração é uma potência de 10, como: $\frac{11}{10}$ e $\frac{39}{100}$, entre muitas. Em outro diálogo acerca do cálculo da expressão $\frac{1}{4}+\frac{1}{100}$, que resultaria em $\frac{25}{100}+\frac{1}{100}=\frac{26}{100}$, A10 mostra dificuldade em obter frações equivalentes e diferenciar duas frações decimais: 


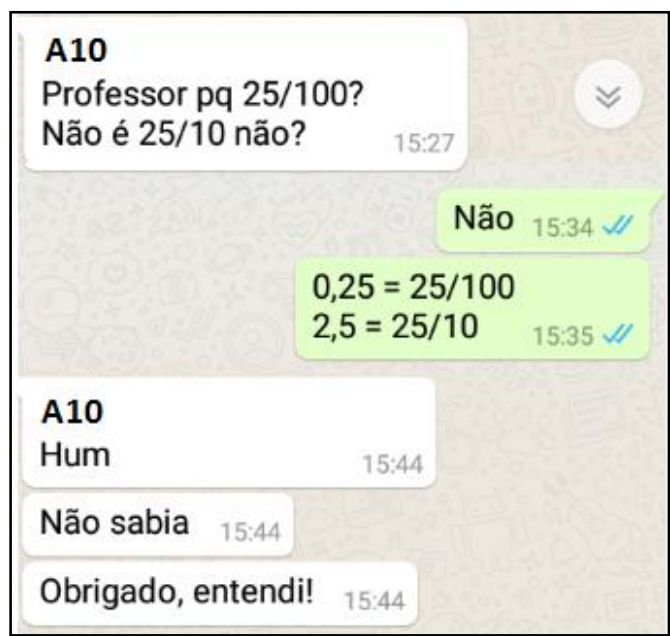

Figura 6 - Dúvida de A10 com resposta do professor Fonte: Elaborado pelos autores.

Visando auxiliar os alunos no entendimento das expressões numéricas, símbolos retirados do ambiente do aplicativo, como figuras de pães e xícaras, foram utilizados estrategicamente como parte de um enunciado para projetar uma estrutura multiplicativa para cada coleção de objetos. Se numa expressão numérica, a operação de multiplicação corresponde a uma estrutura de grupos, os objetos dispostos em linhas e colunas constituem uma reunião de elementos de um conjunto numérico e natural:

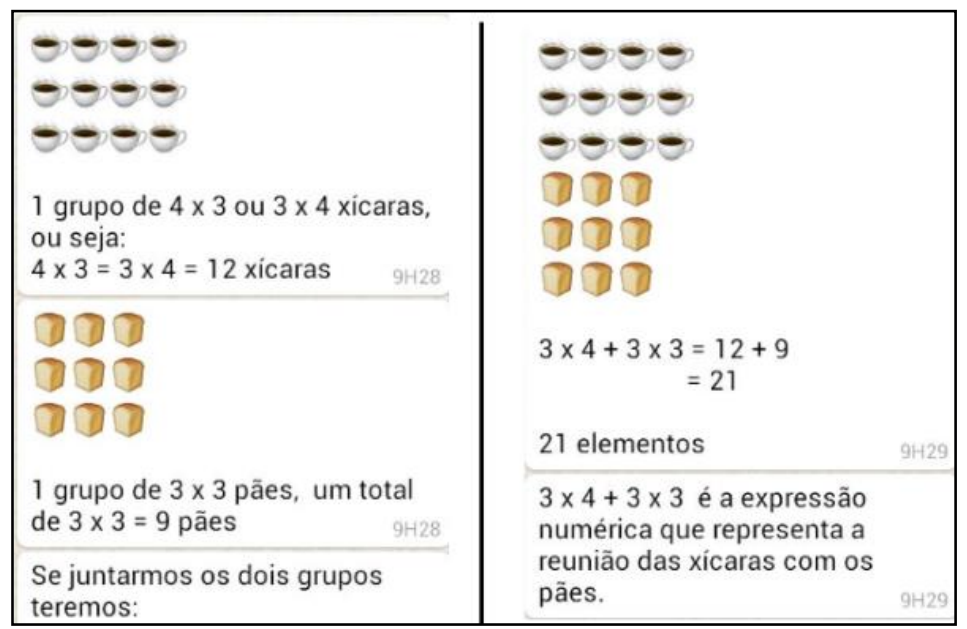

Figura 7 - Exemplo de uma expressão numérica criada pelo professor Fonte: Elaborado pelos autores.

De acordo com o exemplo acima, 3 x $4+3 \times 3$ é a expressão numérica que representa a adição de duas coleções: os símbolos representados pelas doze xícaras e nove pães. O exemplo mostrado com os símbolos no ambiente do aplicativo contribuiu para o entendimento dos alunos sobre o significado de uma expressão numérica. Isso se justifica pelas respostas dos alunos à sugestão de atividade proposta pelo professor mostrada na figura a seguir. Dessa vez, observando o grupo de objetos (bolas e trevos), cada um foi respondendo atividade provocada pelo professor: 


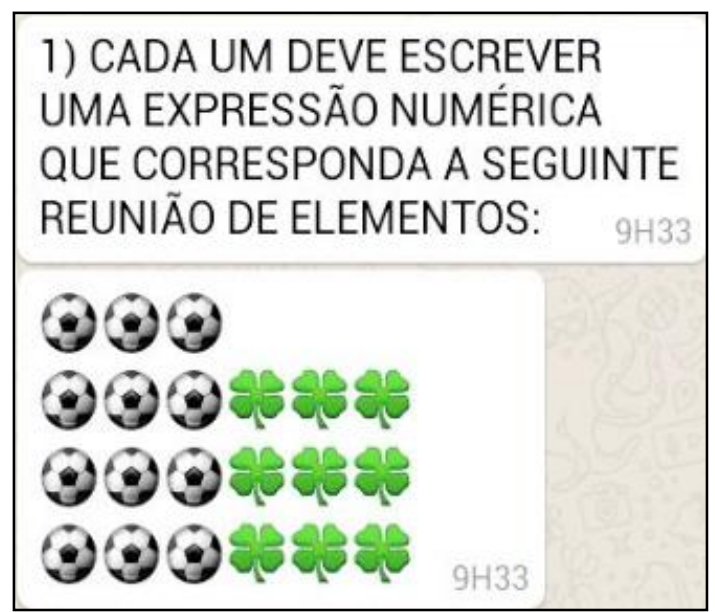

Figura 8 - Sugestão de atividade proposta pelo professor Fonte: Elaborado pelos autores.

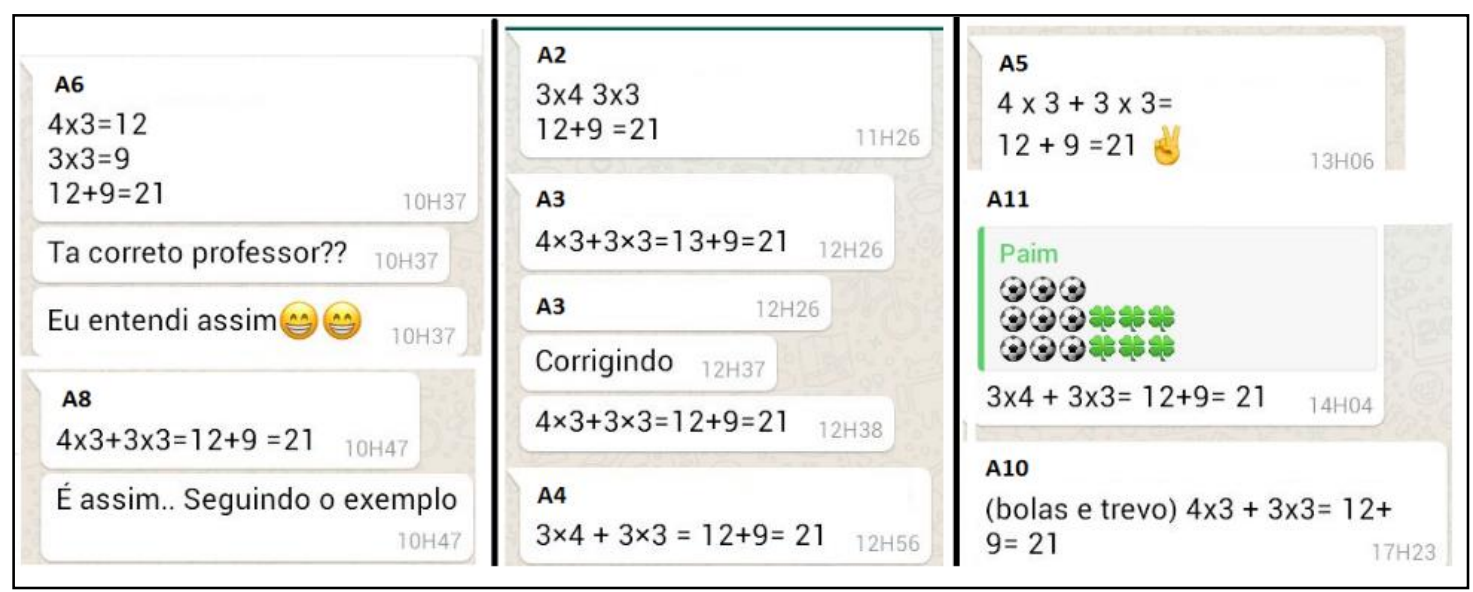

Figura 9 - Sequência das respostas dos alunos participantes Fonte: Elaborado pelos autores.

Ainda assim, surgiram dúvidas quanto a propriedade comutativa da multiplicação. A2 pensa ter se equivocado com a posição do número 4 como fator da multiplicação 3 x 4 e é corrigido imediatamente por A12. Nesse caso, se trata de uma propriedade comutativa da multiplicação dos números naturais, na qual a ordem dos fatores não altera o produto: 3 x $4=4$ x 3. A13 acredita ter errado o sinal de multiplicação:

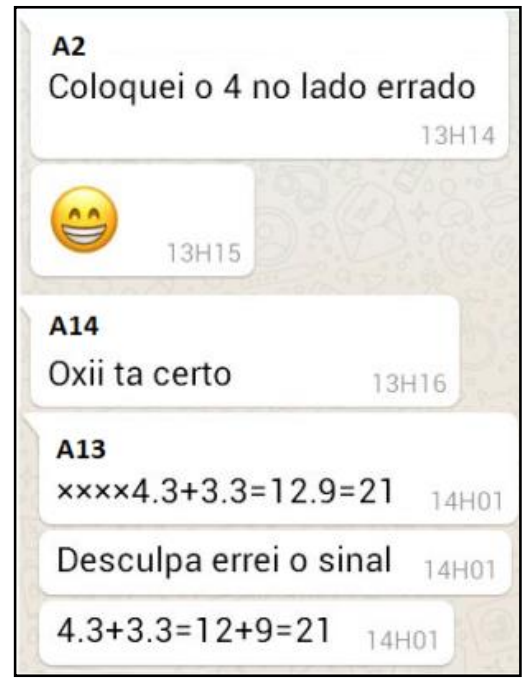

Figura 10 - Dúvida de A2 com participação de A13 e A14 Fonte: Elaborado pelos autores.

ForSci.: r. cient. IFMG, Formiga, v. 6, n. 1, e00339, jan./jun. 2018. 


\section{CONSIDERAÇOES FINAIS}

Considerando o contexto do ambiente ou software de rede social representado pelo WhatsApp como uma ferramenta tecnológica repleta de símbolos que são utilizados para a comunicação entre os usuários desse mesmo ambiente, podemos entender que as transformações provocadas por essa nova realidade abstrata e virtual, anteriormente descritas por Lévy (1998), foram geradas, em grande parte, pela utilização de símbolos que dão significado ao seu funcionamento e, também, pela interação e criação de situações de aprendizagem entre os seus indivíduos.

Segundo Lévy (1998), os ideogramas podem caracterizar símbolos gráficos que representam uma ideia, possuindo relação com fonemas (sons das letras) e palavras (conjunto de fonemas). Logo, se uma linguagem cinematográfica englobar uma frase como uma sequência de palavras (ou um filme como uma sequência de cenas), os símbolos gráficos que constituem o ambiente da rede social podem funcionar como ideogramas que exprimem uma sequência de pensamentos e diferentes formas de comunicação entre os seus usuários. Símbolos que podem ser bem utilizados para o ensino e aprendizagem de conceitos básicos da matemática.

Muitos grupos utilizam ferramentas, softwares ou aplicativos de redes sociais para o compartilhamento de informações e de interesses em comum. Enquanto uns permanecem ligados (linked) por laços familiares ou por relações de amizade, outros partilham do mesmo objetivo: que é o de estar conectado em um ambiente virtual para fins de Educação Matemática à distância.

Dessa forma, refletindo sobre a criação da rede social composta pelo grupo de alunos da EJA para discussão e aprendizagem de conteúdos elementares da matemática básica, podemos afirmar que o avanço tecnológico tem possibilitado uma maior comunicação entre o professor e os seus estudantes no estudo da disciplina mencionada . No grupo citado, muitos alunos residem em locais distantes da escola onde estudam e também permanecem distantes uns dos outros. Devido a esse distanciamento, a rede social funciona como uma sala de aula virtual, um lugar que os une e abriga valores e símbolos úteis para a construção de conhecimentos.

Por meio do software Gephi, podemos ter uma visão da rede de atores participantes do grupo e dos nós de ligação entre eles. Esse software é uma plataforma de visualização de redes baseada na teoria dos grafos, uma ferramenta matemática que possui nós e arestas como linhas ou arcos do grafo.

Através desse suporte, foi possível perceber os conteúdos de maior discussão entre eles, além dos alunos que tiveram mais dúvidas sobre os conteúdos propostos: 


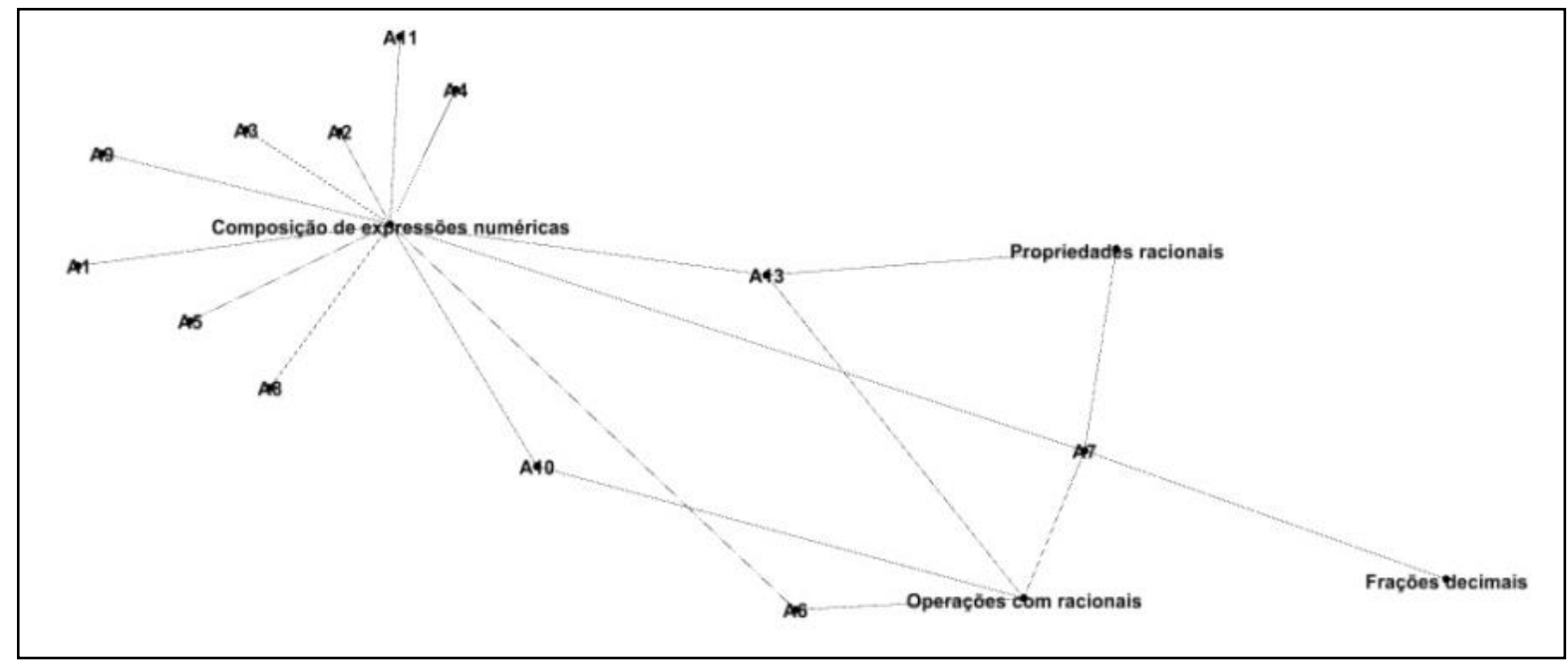

Figura 11 - Nós e atores da rede por meio do software Gephi Fonte: Elaborado pelos autores.

Um dos estudantes que mais interagiu no grupo foi o $\mathrm{A} 7$, ele teve dúvidas em todos os conteúdos. Isso não quer dizer que os demais estudantes não as apresentaram, sendo importante destacar que os questionamentos foram sanados naquele momento, não só com o professor, mas também com outros estudantes, através da interação no ambiente tecnológico.

A origem dos seus e de outros questionamentos pode estar na oferta ou acesso à educação básica do município onde a maioria dos estudantes da EJA que chegam ao Instituto, ou possuem muito tempo fora da escola, ou nunca estudaram as propriedades básicas das operações matemáticas. Contudo, vemos que os estudantes conseguiram escrever a expressão numérica quando procuramos representá-la através das figuras dos objetos disponíveis no ambiente do aplicativo tecnológico.

Dentre as possíveis reflexões tiradas da análise da rede gerada pelo software, as respostas corretas dos alunos, quando escrevem as expressões numéricas, podem caracterizar a diversidade de comunicação nos grupos sociais, em que cada estudante responde à pergunta de acordo com a sua escrita e experiência individual. De fato, isso foi facilitado ao representarmos uma expressão numérica como uma contagem de elementos do cotidiano que pode ser visto nos nossos dias, ou seja, reunir duas coleções de objetos usuais e práticos no dia a dia.

Dos 14 alunos da EJA que iniciaram a dinâmica de interação em grupo, 2 (A1 e A5) tiveram que sair no ano corrente por motivos particulares (saúde, mudança de residência, e outros). Simbolicamente, representamos essa saída por meio da captura de tela da ferramenta celular que comporta a imagem do ambiente virtual:

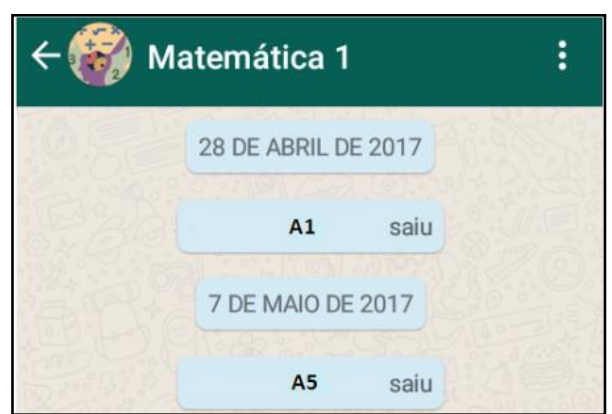

Figura 12 - Saída de A1 e A5 do grupo Fonte: Elaborado pelos autores. 
Mesmo assim, após um ano do começo da nossa interação, o grupo ainda permanece com os 12 alunos restantes e não entraram nem saíram mais alunos deste. A continuidade e manutenção do grupo pelo professor tem o propósito de que se intensifiquem outras discussões sobre questões, conceitos e conteúdos importantes sobre o ensino e a aprendizagem da matemática, atendendo às possíveis dúvidas geradas pelos estudantes dentro desse Ciberespaço enquanto estiverem, ou não, na instituição.

Vale dizer que as informações e os registros dos alunos presentes nesse artigo são uma pequena amostra de como as interações nas redes sociais podem contribuir para o ensino e aprendizagem das disciplinas do ensino básico, principalmente, para a aprendizagem da matemática.

Esperamos que este trabalho possa servir de auxílio para outras pesquisas neste aspecto, o uso do software pode ser útil para discutir, listar e sanar as principais dificuldades dos estudantes no estudo de conceitos de matemática no ensino básico. Entendemos que, nesse contexto, as redes sociais sejam utilizadas para o aperfeiçoamento das práticas pedagógicas de ensino e aprendizagem de matemática em qualquer instituição escolar.

\title{
THE SOCIAL NETWORK AS A SPACE FORDISCUSSION AND LEARNING OF BASIC MATHEMATICAL CONCEPTS
}

\begin{abstract}
This work aims to analyze the learning process of a group of students of Youth and Adult Education of the technical course in Occupational Safety of the Federal Institute of Bahia, Santo Amaro campus, when discussing basic concepts of mathematics in a social media represented by WhatsApp application. In order to identify the types of doubts generated by students in the study of basic mathematics, the records of the students who contributed the most to the group discussions were listed. Appropriating the theoretical concepts of Cyberculture, Dynamic Ideography, Linked and Network Analysis for social media, a network was built presenting its nodes and the quantitative relation between them. The research has a qualitative-quantitative character when it discusses the individual participation of each student in the technological environment and their questioning in relation to the mathematical concepts proposed by the teacher. The results of this work indicate that social media can function as an important environment for discussion and learning of mathematics.
\end{abstract}

Keywords: Basic Mathematics. Social media. Network analysis.

\section{REFERÊNCIAS}

BARABASI, A. Linked: a nova ciência dos networks. São Paulo: Leopardo Editora, 2009.

BENEVENUTO, F. Redes Sociais Online: técnicas de coleta, abordagens de medição e desafios futuros. [S.l: s.n.], [20--?]. Disponível em <http://homepages.dcc.ufmg.br/ fabricio/download/ mini-curso-swib10.pdf/>. Acesso em: 5 dez. 2016.

GOULART, E. Mídias sociais: uma contribuição de análise. [S.1.]: EDIPUCRS, 2014. 
HANNEMAN, R. A.; RIDDLE, M. Introduction to social network methods. Riverside: University of California, Riverside, 2005. Disponível em: 〈http://faculty.ucr.edu/ hanneman/>. Acesso em: 02 out. 2016.

LÉVY, P. Cibercultura. São Paulo: Editora 34, 1999. Loyola, 1998.

A ideografia dinâmica: rumo a uma imaginação artificial? São Paulo: Edições

MALINI, F.; ANTOUN, H. Ciberativismo e mobilização nas redes sociais. Porto Alegre: Sulina, 2013.

RECUERO, R. Redes Sociais na Internet. Porto Alegre: Sulina, 2009.

\section{DADOS DOS AUTORES}

\section{Márcio Antônio Souza Paim}

E-mail: maspaim@hotmail.com.

Currículo lattes: http://lattes.cnpq.br/2175718630649229

Mestre em Gestão e Tecnologias Aplicadas à Educação - GESTEC, pela Universidade do Estado da Bahia. Especialista em Novas Tecnologias para o Ensino da Matemática pela Universidade Federal Fluminense. Licenciado em Matemática pela Universidade Federal da Bahia. Atualmente é professor de matemática do Ensino Básico, Técnico e Tecnológico do Instituto Federal da Bahia, campus de Santo Amaro.

\section{Midiele Dantas Gomes}

E-mail: midieledantas@ hotmail.com

Currículo lattes: http://lattes.cnpq.br/8943391362262772

Mestre em Gestão e Tecnologias aplicadas à Educação. Especialista em Educação Matemática pela Universidade do Estado da Bahia. Atualmente é professora da Universidade Federal do Recôncavo da Bahia.

\section{André Ricardo Magalhães}

E-mail: andrerm@gmail.com

Currículo lattes: http://lattes.cnpq.br/5059926055966737

Doutor em Educação Matemática pela Pontifícia Universidade Católica de São Paulo (PUC - São Paulo). Mestre em Engenharia de Produção pela Universidade Federal de Santa Catarina (UFSC). Especialista em Educação e Novas Tecnologias da Informação (UNEB). Graduado em Informática pela Universidade Católica de Salvador (UNCSAL). Atualmente é coordenador do programa de mestrado em Gestão e Tecnologias aplicadas a Educação na Universidade do Estado da Bahia. 